\title{
Modeling oscillation modal interaction in a hydroelectric generating system
}

\author{
Beibei Xu ${ }^{\mathrm{a}, \mathrm{b}}$, Diyi Chen ${ }^{\mathrm{a}, \mathrm{b}, \mathrm{c}, *}$, Paul Behrens ${ }^{\mathrm{d}, \mathrm{e}}$, Wei Ye ${ }^{\mathrm{a}, \mathrm{b}}$, Pengcheng Guo ${ }^{\mathrm{f}}$, Xingqi Luo ${ }^{\mathrm{f}}$ \\ ${ }^{a}$ Key Laboratory of Agricultural Soil and Water Engineering in Arid and Semiarid Areas, Ministry of Education, Northwest A\&F University, Yangling, \\ Shaanxi 712100, PR China \\ ${ }^{\mathbf{b}}$ Institute of Water Resources and Hydropower Research, Northwest A\&F University, Yangling, Shaanxi 712100, PR China \\ c Curtin Univ, Sch Built Environm, Australasian Joint Res Ctr Bldg Informat Modellin, Bentley, WA 6102, Australia \\ d Leiden University College The Hague, Anna van Buerenplein 301, 2595 DG The Hague, The Netherlands \\ e Institute of Environmental Sciences (CML), Leiden University, PO Box 9518, 2300 RA Leiden, The Netherlands \\ ${ }^{\mathrm{f}}$ State Key Laboratory Based of Eco-hydraulic Engineering in Arid Area, Xi'an University of Technology, Xi'an 710048, Shaanxi, PR China
}

\section{A R T I C L E I N F O}

\section{Keywords:}

Hydroelectric generating systems

Modal interactions

Hydraulic unbalanced forces

Mathematical model

\begin{abstract}
A B S T R A C T
Global hydropower growth continues to accelerate with $25 \%$ of total capacity installed in just the last 10 years. This accelerating expansion and the important storage facility hydropower means it is increasingly important to understand the reasons for operational failures. This is a challenge because the major reason for failures involves the complex interaction of hydraulic, mechanical and electric subsystems. Historically, reliability modelling has been split in two directions, focusing on different sub-systems, and has not yet been unified. Here these approaches are unified with a novel expression of unbalanced forces. This model with operational data are validated and the important modes of oscillation in the shaft are identified. Finally, the mechanism of the first-order oscillation mode exciting a second-order mode is presented. This integrated and accurate mathematical model is a major advance in the diagnosis and prediction of failures in hydropower operation.
\end{abstract}

\section{Introduction}

Hydropower plants have been built in more than 160 countries, with a total of 27,000 hydro-turbine generator units [1]. China is leading the hydropower boom, followed by India, Europe, the United States and Japan [2]. These increases in hydropower capacity have been driven by concerns over climate change and energy security. Presently, it is one of the few technologies offering affordable storage over longer periods, making it a particularly important technology for security of supply [3]. Given these benefits, construction of further hydropower systems is expected to continue, and the growth rate to rise. The economic benefits [3] and carbon dioxide [4] mitigation of these generating systems are well known to the general public, but stability and safety requires attention, with several recent, high-profile failures, such as the accident at the Sayano-Shushenskaya Hydroelectric Power Plant [5]. Failures in hydropower units, at their best, result in capacity reductions and financial loss, and at their worst, injury and death. While operational information is being gathered to better govern hydropower systems (such as load-frequency regulation control methods [6] and refurbishment and uprating of hydro power units [7]), operational managers currently are unable to use this information practically because the underlying system failures are not well understood [8].

Hydropower generation offers a significant challenge to modelers and engineers because it involves sub-systems that interact in complex ways [9]. Historically, studies of these systems have been divided into two research directions: hydro-turbine governing systems [10]; and, shaft systems modeling of hydro-turbine generator units [11]. There are two main issues with these approaches. First, hydro-turbine governing system models attempt to provide stable services to the grid by controlling the speed of the turbine, but ignore shaft axis vibration; conversely, shaft oscillation modeling attempts to control vibrations rather than speed. Clearly these two models interact with each other, hence a general model coupling both viewpoints is increasingly urgent. Second, notwithstanding some early work [12], there have been no significant model developments which included complex water flow and the consequent impact on unbalanced hydraulic forces. This is despite the fact that plant failures caused by this force are very common, for example at the Three Gorges plant [13]. Additionally, with the rapid development of hydropower plants, the size of machined parts is becoming larger and, accordingly, manufacturing precision difficult to maintain. As the precision lowers, the influence of unbalanced forces becomes more important. A more accurate expression of the unbalanced hydraulic force is both important and timely.

\footnotetext{
* Corresponding author at: Institute of Water Resources and Hydropower Research, Northwest A\&F University, Yangling, Shaanxi 712100, PR China.

E-mail address: diyichen@nwsuaf.edu.cn (D. Chen).
} 
The hydro-turbine governing system consists of diversion penstock subsystems, hydraulic turbine subsystems, generator subsystems, and control subsystems. These systems can be described by linear and nonlinear mathematical modelling, and are usually expressed by transfer functions or differential equations. Differences in these model types are driven by differences in the penstock, hydraulic, and generator subsystems. For example, in the penstock system, the transfer function model contains a hyperbolic function from which, using a Taylor expansion, different order polynomials are obtained. The widely used expressions are the zero-order and first-order polynomials, which are named the rigid water hammer model and elastic water hammer model, respectively. In the generator model first- or second-order differential equations are used. Finally, the hydro-turbine governing system can be expressed by differential equations from which numerical results can be obtained using the canonical Runge-Kutta method. Linear models have been widely used in analyzing stability analysis and optimal controller design of the hydro-turbine governing systems. However, there are still many instability problems in operating turbine generator units, especially during transient processes. For example, the Sayano-Shushenskaya hydroelectric generator unit, or the largest power plant in Russian history, suddenly destroyed itself during load rejection and was thrown from its position by water pressure [5]. Seventy-five people died as a result of the catastrophe. All hydroelectric generators in the plant were badly damaged, the turbine hall building was destroyed, and electrical and additional equipment was significantly broken. Commonly, previous studies use simplified linear models, which poorly simulate the dynamical behavior of actual machines. This is especially true for the hydro-turbine governing system due to the complex nonlinear system coupling hydraulic, mechanical, and electrical subsystems. These issues are exacerbated by the scale and complexity of generators and turbines. Given this complexity, it is understandable that linear models present many problems when used in real world conditions.

Nonlinear models of the governing system were mooted some time ago [14], but were rarely used in solving actual problems owing to the lack of efficient theoretical analysis and computational tools. Studies on nonlinear models were revived in 1992 with the development of nonlinear system control theory and improvements in computation [10]. Since then, nonlinear system models have become a key interest in research [15]. Recent studies of the governing system are divided into two main themes. The first theme focusses on the coupling subsystem relationship and effect [16]. For instance, Riasi et al. investigated the effect of surge tank on the safe operation of power plant. The results showed that the surge tank decreases the pressure rise within the spiral case and turbine overspeed by $22 \%$ and $6 \%$, [17]. The second theme is focused on model refinements (for example, the fractional-order model [18], the stochastic model [19], and the Hamiltonian model for single pipe [20] or multiple pipes [21]) and governor control methods (such as the testing measurements [22], the stalling-free control strategies [23], and the fuzzy-PID controller [24]). For example, Xu et al. introduced fractional calculus and utilized fractional stability theory to analyze dynamic operational stability [18]. Mesnage et al. proposed a real-life MPC scheme that considers realistic limitations on the actuator, leading to feasible, almost time-optimal control design [25]. Liang et al proposed a model of hydro-turbine governing system with a surge tank and designed a specified fuzzy mode robust controller [26]. Then, Guo et al established a nonlinear model of the hydro-turbine governing system considering the head loss [27], and surge tank [28], and proposed a corresponding primary frequency relation strategy. Zhang et al proposed an object-oriented approach to establish Matlab/Simulink platform for hydro-turbine governing system [29].

The shaft system of hydro-turbine generator units consists of the upper guide bearing, the generator rotor, the lower guide bearing, the water guide bearing, and the turbine runner. It is a typical, bearingrotor rotational machine system upon which several forces act, including: the unbalanced magnetic force (of the generating inductor), the oil film force (the oil film used on the bearings), and the unbalanced hydraulic force (the mechanical forces of the water flow). By understanding the effects and interaction of each of these forces it is possible to predict the dynamic responses of turbines and diagnose possible unit failures [30]. Each of these forces has been previously investigated independently, and the major advancements in the first two forces are outlined in turn. The first formulation of the unbalanced magnetic force was used to analyze the effects of coupling misalignment on the vibrations of rotating machinery, such as the bladed disks [31] and hydraulic turbines [32]. A more generalized, force equation model was developed incorporating the actual air gap distribution inside the stator, regardless of the orbit type [33]. Recently, studies have focused on calculating the forces in different types of generator, such as the generator rotor [34], tidal turbine [35], and Francis turbine [36].

Three main contributions are concluded in this study. First, by using a novel expression of the unbalanced hydraulic force relative to the runner axis a general, unified model of the hydroelectric generating system is proposed. Second, the interaction of these subsystems and oscillation modes are obtained on the basis of this model. Finally, this model is validated against the existing theory (linear and nonlinear series methods) and operational data.

\section{A unified model of a hydroelectric generation system}

A hydroelectric generation system is composed of diversion penstocks (the hydraulic subsystem), hydraulic turbine generator units (the mechanic-electric coupling subsystem), and auxiliary equipment (the mechanical subsystem). The operating state of a hydraulic turbine is easily disturbed owing to the complex motion of water flowing in diversion penstocks, multi-operating mode conversion, etc. While it might be possible to control the shaft oscillations due to these disturbances, the turbine still needs to meet the requirements of electricity on the grid, such that the change in frequency of the turbine is limited (typically to within $0.5 \mathrm{~Hz}$ ). With this in mind, the model unification with the canonical models are established from the literature for a hydro-turbine governing system [19] and a shaft system [37].

\subsection{Hydro-turbine governing system model}

Here a nonlinear mathematical model of the hydro-turbine governing system is adopted as [19]:

$$
\left\{\begin{array}{l}
\dot{x}_{1}=x_{2} \\
\dot{x}_{2}=x_{3} \\
\dot{x}_{3}=\frac{\pi^{2}}{T_{01}^{2}} x_{2}+\frac{1}{Z_{01} T_{01}^{3}}\left(h_{0}-f q^{2}-h_{q T}-\frac{y_{r}^{2}}{y^{2}} q^{2}\right) \\
\dot{q}=-3 \pi^{2} x_{2}+\frac{4}{Z_{01} T_{01}}\left(h_{0}-f q^{2}-h_{q T}-\frac{y_{r}^{2}}{y^{2}} q^{2}\right) \\
\dot{\omega}=\frac{1}{T_{a b}}\left(m_{t}-m_{e}-e_{n} \omega\right)
\end{array}\right.
$$

where $T_{01}$ is the elastic time constant of the penstock system, $T_{01}=L / v$; $L$ is the length of the penstock; $v$ is the speed of the surge pressure wave in the penstock; $Z_{01}$ is the resistance value of the hydraulic surge in the penstock system, $Z_{01}=v Q_{\mathrm{r}} / A g H_{\mathrm{r}} ; Q_{r}$ is the rated flow of the hydroturbine; $H_{\mathrm{r}}$ is the rated head of the hydro-turbine. $g$ is the acceleration of gravity; $A$ is the cross-sectional area of the penstock; $h_{0}$ is a difference of water head between the upstream and downstream; $f_{1}$ is the friction factor of the penstock; $y_{r}$ is the rated value of the guide vane; $m_{t}$ is the turbine torque; $m_{e}$ is the electromagnetic torque of the generator; $e_{n}$ is the is the accommodation coefficient; $k_{p}$ is the proportional gain; $k_{i}$ is the integral gain; $k_{d}$ is the differential gain; $y_{0}$ is the initial condition of the guide vane; $r$ is the load disturbance; $x_{1}, x_{2}, x_{3}$, and $x_{4}$ are the middle variables; $q$ is the turbine flow; $\omega$ is the generator speed; $y$ is the guide vane opening. 


\subsection{Shaft system model}

The shaft system of the generator unit is described as [38]:

$\left\{\begin{aligned} \dot{x}= & v_{x} \\ \dot{y}= & v_{y} \\ \dot{v}_{x}= & \frac{1}{m_{1}+m_{2}}\left(-c v_{x}-\left(k_{1}+k_{2}\right) v_{x}+\left(m_{1} e_{1}+m_{2} e_{2}\right) \omega^{2} \cos \varphi-k_{2} r \cos \theta\right. \\ & \left.+m_{2} r \omega^{2} \cos \theta+F_{x-u m p}+F_{x}\right) \\ \dot{v}_{y}= & \frac{1}{m_{1}+m_{2}}\left(-c v_{y}-\left(k_{1}+k_{2}\right) v_{y}+\left(m_{1} e_{1}+m_{2} e_{2}\right) \omega^{2} \sin \varphi-k_{2} r \sin \theta\right. \\ & \left.+m_{2} r \omega^{2} \sin \theta+F_{y-u m p}+F_{y}\right)\end{aligned}\right.$

where $x$ and $y$ are the rotor axis of the generator in X-direction and Ydirection, respectively; $v_{x}$ and $v_{y}$ are the velocity of axis in X-direction and Y-direction, respectively; $m_{1}$ and $m_{2}$ are the generator rotor mass and the turbine runner mass, respectively; $c$ is the damping coefficient; $k_{1}$ is the bearing stiffness of the generator rotor; $k_{2}$ is the bearing stiffness of the hydro-turbine runner; $e_{1}$ is the eccentric mass of the generator rotor; $e_{2}$ is the eccentric mass of the hydro-turbine runner; $\omega$ is the generator speed; $\varphi$ is the phase of the generator rotor; $\theta$ is the phase of the turbine runner; $r$ is the distance between the axis of the turbine runner and the generator rotor; $F_{x \text {-ump }}$ and $F_{y \text {-ump }}$ are the asymmetric magnetic pull forces in X-direction and Y-direction, respectively; $F_{x}$ and $F_{y}$ are the oil-film forces in X-direction and Y-direction, respectively.

\subsection{A unified model}

The unbalanced hydraulic force is generally caused by asymmetric flow through the unit, for example along the runner blades, the guide vane, and the socket ring. Tong et al. proposed an expression for the force on the runner blade of [12]:

$R=\rho W_{m a} \Gamma_{a}$

where $W_{\text {ma }}$ is the average value of the relative velocity around the blade; $\Gamma_{a}$ is the average circulation. Utilizing Kutta-Zhoukowski condition, the force can be detailed as:

$P_{m}=C_{y} \times \frac{\gamma}{g} \times \frac{W_{m}^{2}}{2} \times \frac{F}{\cos \lambda} \times \cos \left(\beta_{m}-\lambda\right)$

where $F$ is the maximum area of the blade; $W_{m}$ is average value of the relative flow velocity of the blade front $\left(W_{1}\right)$ and back flow $\left(W_{2}\right)$, $W_{\mathrm{m}}=\left(W_{1} W_{2}\right)^{0.5} \beta_{m}$ is the angle between the average flow velocity and the blade in the circumferential direction; $\gamma$ is the weight of water, $\gamma=\rho g ; C_{y}$ is the lift coefficient of the blade; $C_{x}$ is the damping coefficient of the blade, $\lambda=\arctan \left(C_{x} / C_{y}\right)$. Applying the approximate expressions of the lift coefficient and the damping coefficient to the blade gives:

$\left\{\begin{array}{l}C_{x}=2 \sin \left(\frac{\arcsin C_{y}}{2}\right)^{2} \\ \lambda=\arctan \frac{C_{x}}{C_{y}}=\arctan \frac{2 \sin \left(\frac{\arcsin C_{y}}{2}\right)^{2}}{C_{y}}\end{array}\right.$

There are three motion types in the turbine runner, which are defined as the relative velocity $(W)$, the convected velocity $(U)$ and the absolute velocity $(V)$. An example of this, for a Francis turbine runner along with the velocity triangle of the blade are shown in Fig. 1. Subscript 1 represents the flow velocities of the blade at the inlet, and subscript 2 describes the flow velocities of the blade at the outlet. $\beta$ is the direction angle of relative velocity $(W) . \alpha$ is the direction angle of absolute velocity $(V)$.

The relative flow velocity at the inlet is then:

$W_{1}=\frac{V_{\mathrm{m} 1}}{\sin \beta_{1}}=\frac{Q / F_{1}}{\sin \beta_{1}}=\frac{Q}{\psi_{1} \pi D_{1} \mathrm{~b}_{0} \sin \beta_{1}}$

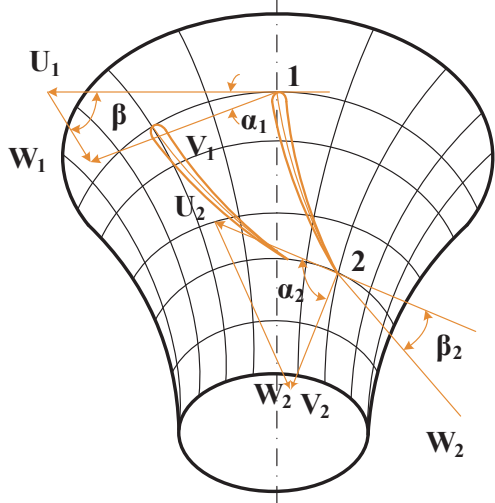

Fig. 1. Francis turbine runner and the velocity triangle of the blade.

where $Q$ is the turbine flow; $D_{1}$ is the diameter of the turbine runner at the inlet; $b_{0}$ is the height of the blade; $\psi_{1}$ is the coefficient of flow reduction over the cross section of the blade due to blade thickness at the inlet.

From the velocity triangle, the relative flow velocity at the outlet is written as:

$W_{2}=\frac{V_{m 2}}{\sin \beta_{2}}=\frac{Q / F_{2}}{\sin \beta_{2}}=\frac{Q}{\psi_{2} \pi D_{2}^{2} \sin \beta_{2}}$

Here, the direction of the convected velocity is defined as $x$-axis. The coordinates of the velocity $W_{1}, W_{2}$ and the velocity $W_{\mathrm{m}}$ are $\left(W_{1} \cos \beta_{1}, W_{1} \sin \beta_{1}\right),\left(W_{2} \cos \beta_{2}, W_{2} \sin \beta_{2}\right)$, and $\left(W_{1} \cos \beta_{1}+W_{2} \cos \beta_{2}\right.$, $W_{1} \sin \beta_{1}+W_{2} \sin \beta_{2}$ ), respectively. Then the absolute value of $W_{\mathrm{m}}$ is written as:

$\left|\vec{W}_{m}\right|=\frac{1}{2} \sqrt{\left|\vec{W}_{1}\right|^{2}+\left|\vec{W}_{2}\right|^{2}+2 \vec{W}_{2} \vec{W}_{1} \cos \left(\beta_{2}-\beta_{1}\right)}$

$=\frac{1}{2} \sqrt{\frac{Q^{2}}{\left(\psi_{1} \pi D_{1} b_{0} \sin \beta_{1}\right)^{2}}+\frac{Q^{2}}{\left(\psi_{2} \pi D_{2}{ }^{4} \sin \beta_{2}\right)^{2}}+\frac{2 Q^{2} \cos \left(\beta_{2}-\beta_{1}\right)}{\psi_{1} \psi_{2} \pi^{2} D_{1} D_{2}^{2} b_{0} \sin \beta_{1} \sin \beta_{2}}}$ then:

The angle between the velocity $W_{\mathrm{m}}$ and the convected velocity is

$\beta_{m}=a \sin \left(\frac{W_{1} \sin \beta_{1}+W_{2} \sin \beta_{2}}{\left|\vec{W}_{m}\right|}\right)$

In light of Eqs. (8) and (9), Eq. (4) is rewritten as:

$$
\begin{aligned}
P_{m}= & \frac{\gamma C_{y} F \cos \left(\beta_{m}-\lambda\right)}{4 g \cos \lambda}\left(\frac{Q^{2}}{\left(\psi_{1} \pi D_{1} b_{0} \sin \beta_{1}\right)^{2}}+\frac{Q^{2}}{\left(\psi_{2} \pi D_{2}^{4} \sin \beta_{2}\right)^{2}}\right. \\
& \left.+\frac{2 Q^{2} \cos \left(\beta_{2}-\beta_{1}\right)}{\psi_{1} \psi_{2} \pi^{2} D_{1} D_{2}^{2} b_{0} \sin \beta_{1} \sin \beta_{2}}\right)
\end{aligned}
$$

Assuming that the initial angle of the blade is $\alpha_{0}$, the position angle of the blade at time $t$ can be described as:

$\alpha=\alpha_{0}+\omega t$

The component forces of $P_{m}$ in the $X$-direction and $Y$-direction are then:$$
\left\{\begin{aligned}
P_{x}= & \frac{C_{y} \gamma F \cos \alpha \cos \left(\beta_{m}-\lambda\right)}{8 g \cos \lambda}\left(\frac{Q^{2}}{\left(\psi_{1} \pi D_{1} b_{0} \sin \beta_{1}\right)^{2}}+\frac{Q^{2}}{\left(\psi_{2} \pi D_{2}{ }^{4} \sin \beta_{2}\right)^{2}}\right. \\
& \left.+\frac{2 Q^{2} \cos \left(\beta_{2}-\beta_{1}\right)}{\psi_{1} \psi_{2} \pi^{2} D_{1} D_{2}^{2} b_{0} \sin \beta_{1} \sin \beta_{2}}\right) \\
P_{y}= & \frac{C_{y} \gamma F \sin \alpha \cos \left(\beta_{m}-\lambda\right)}{8 g \cos \lambda}\left(\frac{Q^{2}}{\left(\psi_{1} \pi D_{1} b_{0} \sin \beta_{1}\right)^{2}}+\frac{Q^{2}}{\left(\psi_{2} \pi D_{2}{ }^{4} \sin \beta_{2}\right)^{2}}\right. \\
& \left.+\frac{2 Q^{2} \cos \left(\beta_{2}-\beta_{1}\right)}{\psi_{1} \psi_{2} \pi^{2} D_{1} D_{2}^{2} b_{0} \sin \beta_{1} \sin \beta_{2}}\right)
\end{aligned}\right.
$$

Theoretically, water flowing in the turbine runner is axisymmetric, but in practice manufacturing deviations of the blade can induce radial asymmetry and forces relative to the center of the turbine runner. For 
example, assume a pair of 'real' runner blades (numbered 1 and 13) with manufacturing deviations. The relative velocity at the outlet edge is defined as $W_{21}$. The angle between the relative velocity and the circumferential direction of blade 1 is $\beta_{21}$. The relative velocities for the other blades are $W_{22}$. The angle between the relative velocity and the circumferential direction of convected velocity is $\beta_{22}$. The angle between the velocity $W_{21}$ and the convected velocity is $\beta_{m 1}$. The relationship is then:

$\beta_{m 1}=a \sin \left(\frac{W_{1} \sin \beta_{1}+W_{21} \sin \beta_{21}}{\left|\vec{W}_{m 1}\right|}\right)$

The angle between the velocity $W_{22}$ and the convected velocity for other blades is $\beta_{\mathrm{m} 2}$, giving the relationship:

$\beta_{m 2}=a \sin \left(\frac{W_{1} \sin \beta_{1}+W_{22} \sin \beta_{22}}{\left|\vec{W}_{m 2}\right|}\right)$

The hydraulic unbalanced forces can then be expressed as:

$\left\{\begin{array}{c}P_{x}=C_{y} \frac{\gamma}{g}|\cos \alpha| \frac{F}{8 \cos \lambda}\left[A_{1} \cos \left(\beta_{m 1}-\lambda\right)-A_{2} \cos \left(\beta_{m 2}-\lambda\right)\right] \\ P_{y}=C_{y} \frac{\gamma}{g}|\sin \alpha| \frac{F}{8 \cos \lambda}\left[A_{1} \cos \left(\beta_{m 1}-\lambda\right)-A_{2} \cos \left(\beta_{m 2}-\lambda\right)\right]\end{array}\right.$

where $\left\{\begin{array}{l}A_{1}=\frac{Q^{2}}{\left(\psi_{1} \pi D_{1} b_{0} \sin \beta_{1}\right)^{2}}+\frac{Q^{2}}{\left(\psi_{2} \pi D_{2}{ }^{4} \sin \beta_{21}\right)^{2}}+\frac{2 Q^{2}}{\psi_{1} \psi_{2} \pi^{2} D_{1} D_{2}{ }^{2} b_{0} \sin \beta_{1} \sin \beta_{21}} \\ A_{2}=\frac{Q^{2}}{\left(\psi_{1} \pi D_{1} b_{0} \sin \beta_{1}\right)^{2}}+\frac{Q^{2}}{\left(\psi_{2} \pi D_{2}{ }^{4} \sin \beta_{22}\right)^{2}}+\frac{2 Q^{2}}{\psi_{1} \psi_{2} \pi^{2} D_{1} D_{2}{ }^{2} b_{0} \sin \beta_{1} \sin \beta_{22}}\end{array}\right.$.

The dynamic torque of the hydraulic turbine considering the hydraulic unbalanced forces is rewritten as:

$$
\begin{aligned}
m_{t}= & \frac{12}{13} \rho Q\left[\left(\frac{\cot \alpha}{b_{0}}+\frac{r_{2} \eta_{0}}{F_{2} \varphi} \cot \beta_{21}\right) \frac{12}{13} Q-\omega r_{2}^{2}\right] \\
& +\frac{1}{13} \rho Q\left[\left(\frac{\cot \alpha}{b_{0}}+\frac{r_{2} \eta_{0}}{F_{2} \varphi} \cot \beta_{22}\right) \frac{1}{13} Q-\omega r_{2}^{2}\right]
\end{aligned}
$$

Similarly, the generator speed is derived as:

$$
\begin{aligned}
\dot{\omega}= & \frac{1}{T_{a b}}\left\{\frac{12}{13} \frac{\rho Q}{M_{g B}}\left[\left(\frac{\cot \alpha}{b_{0}}+\frac{r_{2} \eta_{0}}{F_{2} \varphi} \cot \beta_{21}\right) \frac{12}{13} Q-\omega r_{2}^{2}\right]\right. \\
& \left.+\frac{\rho Q}{13 M_{g B}}\left[\left(\frac{\cot \alpha}{b_{0}}+\frac{r_{2} \eta_{0}}{F_{2} \varphi} \cot \beta_{22}\right) \frac{1}{13} Q-\omega r_{2}^{2}\right]-e_{n} x-m_{g 0}\right\}
\end{aligned}
$$

Finally, incorporating these forces gives us a unified model of:
These equations of the hydro-turbine governing system, consisting of the hydraulic subsystem, the electric subsystem and the guide vane opening equation, are linked by a simple nonlinear turbine torque $\left(m_{t}=A_{t} h_{t}\left(q_{t}-q_{n l}\right)-D_{t} \omega\right)$ proposed by [10]. The representation of the shaft subsystem only includes the mechanical subsystem except for the guide vane opening equation and the unbalanced hydraulic forces acting on the turbine blade.

\section{Nonlinear modal series method}

The model of the generating system, Eq. (18), can be written as the following type [39]:

$\dot{X}=F(X)$

where $X_{\text {sep }}$ is a vector describing the equilibrium point of the system. Using a Taylor expansion, this equilibrium point can be given as:

$\dot{X}=A X+\frac{1}{2}\left[\begin{array}{c}X^{T} H_{1} X \\ X^{T} H_{2} X \\ X^{T} H_{3} X \\ X^{T} H_{4} X \\ X^{T} H_{5} X \\ X^{T} H_{6} X \\ X^{T} H_{7} X \\ X^{T} H_{8} X \\ X^{T} H_{9} X \\ X^{T} H_{10} X \\ X^{T} H_{11} X\end{array}\right]+\ldots$

where $X$ is the domain of convergence; $A$ is the Jacobian matrix, $A=\left[\frac{\partial F_{i}}{\partial X}\right]_{X=X_{\text {sep }}}$, and $i=1,2, \ldots, 11 . H_{i}$ is the Hessian matrix, $H_{i}=\left[\frac{\partial^{2} F_{i}}{\partial x_{k} \partial x_{l}}\right]_{X=X_{\text {sep }}}$ and $\left\{\begin{array}{l}l=1,2, \ldots, 11 \\ k=1,2, \ldots, 11\end{array}\right.$.

Using the relationship $X=U Y$, Eq. (20) is rewritten as:

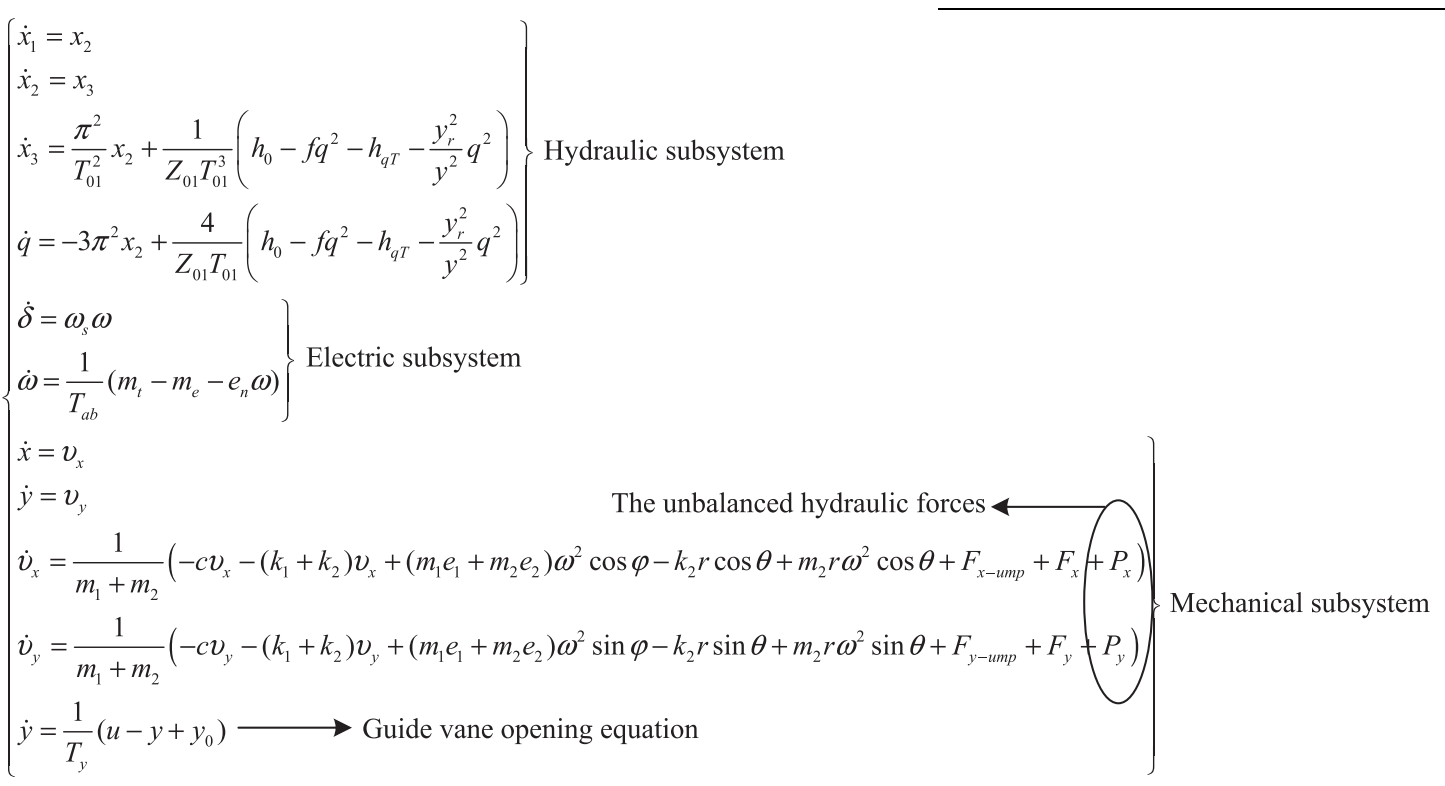




$$
\dot{Y}=\Lambda Y+\frac{1}{2} V\left[\begin{array}{c}
Y^{T}\left(U^{T} H_{1} U\right) Y \\
Y^{T}\left(U^{T} H_{2} U\right) Y \\
Y^{T}\left(U^{T} H_{3} U\right) Y \\
Y^{T}\left(U^{T} H_{4} U\right) Y \\
Y^{T}\left(U^{T} H_{5} U\right) Y \\
Y^{T}\left(U^{T} H_{6} U\right) Y \\
Y^{T}\left(U^{T} H_{7} U\right) Y \\
Y^{T}\left(U^{T} H_{8} U\right) Y \\
Y^{T}\left(U^{T} H_{9} U\right) Y \\
Y^{T}\left(U^{T} H_{10} U\right) Y \\
Y^{T}\left(U^{T} H_{11} U\right) Y
\end{array}\right]+\ldots
$$

where $X$ describes the equilibrium point, $Y$ describes the transformed system and $U$ are eigentriplets of the system [40]; $V$ is a different set of eigentriplets, $\Lambda$ is the diagonal matrix of eigenvalue $\lambda_{i}$, with an expression:

$\Lambda=\left[\begin{array}{llllll}\lambda_{1} & & & & & \\ & \lambda_{2} & & & & \\ & & \lambda_{3} & & & \\ & & & \lambda_{4} & & \\ & & & & & \lambda_{11}\end{array}\right]$.

These eigenvalues $\lambda$ can be thought of as the characteristic value of the generating system. In light of the above analysis, Eq. (21) can be rewritten as:

$\dot{y}_{j}=\lambda_{j} y_{j}+\sum_{k=1}^{11} \sum_{l=1}^{11} C_{k l}^{j} y_{k} y_{l}+\ldots$

where $\left[C_{k l}^{j}\right]=\frac{1}{2} \sum_{p=1}^{11} V_{j p}\left[U^{T} H_{p} U\right], V_{j p}$ represents the matrix element of $U_{j p}^{-1}$ in row $i$ line $p$. Set the initial value of the system as $X_{0}$, and the initial value of transformed system $Y$ is obtained as $Y_{0}=U^{-1} X^{0}$, $Y_{0}=\left[y_{10}, y_{20}, \ldots, y_{110}\right]$. Assuming that the solution of Eq. (22) is $y_{j}\left(Y_{0}, t\right)$, the expressions is reduced to the relationship:

$y_{j}(t)=y_{1 j}(t)+y_{2 j}(t)+y_{3 j}(t)+\ldots$

where $y_{m j}(t)$ contains the combination of initial states. From prior studies, when $m=2$, the simulation results could meet the accuracy requirement (since each increasing order yields smaller perturbations). Therefore, if just the first two orders are focused, from Eq. (21), Eq. (20) is write:

$\dot{y}_{1 j}+\dot{y}_{2 j}=\lambda_{j}\left(y_{1 j}+y_{2 j}\right)+\sum_{k=1}^{11} \sum_{l=1}^{11} C_{k l}^{j}\left(y_{1 k}+y_{2 k}\right)\left(y_{1 l}+y_{2 l}\right)$

To solve Eq. (24) an inverse Laplace transformation is applied, to give:

$$
\begin{aligned}
& y_{j}(t)=y_{1 j}(t)+y_{2 j}(t)=y_{j 0} e^{\lambda_{j} t}+\sum_{k=1}^{11} \sum_{l=1}^{11} C_{k l}^{j} S_{k l}^{j}(t) \\
& =\left\{y_{j 0}-\left\{\sum_{k=1}^{11} \sum_{l=1}^{11} h 2_{k l}^{j} y_{k 0} y_{l 0}\right\}_{(k, l, j) \notin R_{2}^{\prime}}\right) e^{\lambda_{j} t} \\
& +\left\{\sum_{k=1}^{11} \sum_{l=1}^{11} h 2_{k l}^{j} y_{k 0} y_{l 0} e^{\left(\lambda_{k}+\lambda_{l}\right) t}\right\}_{(k, l, j) \notin R_{2}^{\prime}} \\
& +\left\{\left(\sum_{k=1}^{11} \sum_{l=1}^{11} C_{k l}^{j} y_{k 0} y_{l 0}\right) t e^{\lambda_{j} t}\right\}_{(k, l, j) \in R_{2}^{\prime}}
\end{aligned}
$$

When $\left|\lambda_{k}+\lambda_{l}-\lambda_{j}\right| \leqslant 0.001\left|\lambda_{j}\right|$, the combination causing the second order quasi-resonant frequency is $(k, l, j)$. Expression of symbol $h 2_{k l}^{j}$ is $h 2_{k l}^{j}=\frac{C_{k l}^{j}}{\lambda_{k}+\lambda_{l}+\lambda_{j}}$. Utilizing the relationship $X=U Y$, Eq. (25) is rewritten as:

$$
\begin{aligned}
x_{i}(t)= & \sum_{j=1}^{11} u_{i j}\left(y_{j 0}-\left\{\sum_{k=1}^{11} \sum_{l=1}^{11} h 2_{k l}^{j} y_{k 0} y_{l 0}\right\}_{(k, l, j) \notin R^{\prime} 2}\right) e^{\lambda_{j} t} \\
& +\sum_{j=1}^{11} u_{i j}\left\{\sum_{k=1}^{11} \sum_{l=1}^{11} h 2_{k l}^{j} y_{k 0} y_{l 0} e^{\left(\lambda_{k}+\lambda_{l}\right) t}\right\}_{(k, l, j) \notin R^{\prime} 2} \\
+ & \left\{\sum_{j=1}^{11}\left(\sum_{k=1}^{11} \sum_{l=1}^{11} u_{i j} C_{k l}^{j} y_{k 0} y_{l 0}\right) t e^{\lambda_{j} t}\right\}_{(k, l, j) \in R_{2}^{\prime}}
\end{aligned}
$$

From Eq. (26), the linear expression of the dynamic variable $x_{i}$ in the system is

$x_{i}(t)=\sum_{j=1}^{11} u_{i j} y_{j 0} e^{\lambda_{j} t}$

where $y_{j 0}$ is the $j$-th component of $Y_{0}=U^{-1} X_{0}, X_{0}$ is the initial condition of variable $X$.

Assuming that only variable $x_{i}$ is disturbed with amplitude of value 1 , and other variables are defined as 0 . According to the relationship of $V=U^{-1}$, the initial condition of variable $y_{j 0}$ is rewritten as:

$y_{j 0}=v_{j i}$

From Eq. (28), the response of variable $x_{i}$ is

$x_{i}(t)=\sum_{j=1}^{11} u_{i j} v_{j i} e^{\lambda_{j} t}$

The linear participation factor $P_{i j}$ describes the linear effect of oscillation type $j$ on state variable $x_{i}$, namely the excited degree of oscillation type $j$ in variable $i$ when the system is disturbed. Its equation is defined as:

$P_{i j}=u_{i j} v_{j i}$

Similarly, the above method solving the linear participation factor is applied to the generating system, and the second-order participation factor of the system can be obtained by evaluating Eq. (28) with Eq. (26):

$$
\begin{aligned}
& x_{i}(t)=\sum_{j=1}^{11} u_{i j}\left(v_{j i}-\left\{\sum_{k=1}^{11} \sum_{l=1}^{11} h 2_{k l}^{j} v_{k i} v_{l i}\right\}_{(k, l, j) \notin R_{2}^{\prime}}\right) e^{\lambda_{j} t} \\
& +\sum_{j=1}^{11} u_{i j}\left\{\sum_{k=1}^{11} \sum_{l=1}^{11} h 2_{k l}^{j} v_{k i} v_{l i} e^{\left(\lambda_{k}+\lambda_{l}\right) t}\right\}_{(k, l, j) \notin R_{2}^{\prime}} \\
& +\left\{\sum_{j=1}^{11}\left(\sum_{k=1}^{11} \sum_{l=1}^{11} u_{i j} C_{k l}^{j} v_{k i} v_{l i}\right) t e^{\lambda_{j} t}\right\}_{(k, l, j) \in R_{2}^{\prime}}
\end{aligned}
$$

From the definition of linear participation factor, Eq. (29) can be transformed for a non-linear analysis as:

$x_{i}(t)=\sum_{j=1}^{11} P 2_{i j} e^{\lambda_{j} t}+\sum_{k=1}^{11} \sum_{l=1}^{11} P 2_{k l}^{i} e^{\left(\lambda_{k}+\lambda_{l}\right) t}+\sum_{j=1}^{11} P 2_{(k, l, j)}^{i} t e^{\lambda_{j} t}$

where $P 2_{i j}=u_{i j}\left(v_{j i}-\left\{\sum_{k=1}^{11} \sum_{l=1}^{11} h 2_{k l}^{j} v_{k i} v_{l i}\right\}\right)_{(k, l, j) \notin R^{\prime} 2}, P 2_{k l}^{i}=\left(\sum_{j=1}^{11} u_{i j} h 2_{k l}^{j} v_{k i} v_{l i}\right)_{(k, l, j) \notin R_{2}^{\prime}}$, and $P 2_{(k, l, j)}^{i}=\left(\sum_{k=1}^{11} \sum_{l=1}^{11} u_{i j} C_{k l}^{j} v_{k i} v_{l i}\right)_{(k, l, j) \in R_{2}^{\prime}}$.

\section{Results and discussions}

Now, the model is validated against linear and nonlinear modal series analysis, and operational data. Using nonlinear modal series analysis, it is possible to capture the high-frequency oscillation modes of nonlinear dynamical systems, giving a good physical insight into oscillation interactions (such as the upstream disturbance on the drafttube on the basis of system model [41], experiment investigated of load variations on pressure fluctuations [42], and common mode noise analysis [43]). Importantly it gives a closed-form approximate solution 
to the nonlinear state equations even in the face of a resonance condition, which has been a weakness of previous approaches (full details are in Supplementary Note 1).

Supplementary data associated with this article can be found, in the online version, at https://doi.org/10.1016/j.enconman.2018.08.034.

\subsection{Model validation}

Modal analysis yields two important parameters for further discussion. The first is the eigenvalues of the system $\lambda$ - which can be thought of as the characteristic values of the generating system. The second is the participation factors $P$ which describes the interaction effects of variables within the system. Participation factors may be either firstorder or second-order. The second-order participation factor, which is of specific interest because it describes the non-linear components of the system, can be divided into three types. First, the single modal participation factor $P 2_{i j}$ where 2 indicates the second order, $i$ the system state variable $x_{i}$ and $j$ the oscillation types (namely the eigenvalue of the system). Second the composite pattern participation factor $P 2_{k l}^{i}$ given by the interaction effect between state variables and the compound oscillation types $(k, l)$. Finally, the resonance mode participation factor $P 2^{i}{ }_{(k, l, j)}$ represents the interaction effect between the system state variable $x_{i}$ and compound oscillation types $(k, l, j)$. For a full description of the mathematical background for linear and nonlinear modal analysis see Section 3.

As described above, the shaft subsystem is dependent on the axis offset, and the governing system is dependent on the generator speed. Regarding the numerical method, at least one of widely applied methods should be selected and used to validate the robustness of the nonlinear modal series method of Eq. (18). Fortunately, the RungaKutta method is a widely accepted method and is robust in solving differential equations like Eq. (18). Hence, it is selected to validate the feasibility of the nonlinear modal series by obtaining the approximate solution of Eq. (18). To enhance the robustness of the nonlinear modal series method, the Admas-Bashforth-Moulton algorithm $[18,45]$ is selected to further simulate the response of Eq. (18). The hydro-turbine flow, the generator speed, and the axis offsets in $\mathrm{X}$ and $\mathrm{Y}$ directions are investigated using by linear modal analysis, nonlinear modal analysis, and the Runge-Kutta method in Fig. 2.

The linear method results are clearly different to those of the nonlinear modal series, the Runge-Kutta method, and the Admas-BashforthMoulton algorithm. The nonlinear modal series, the Admas-BashforthMoulton algorithm, and the Runge-Kutta results show good agreement, at least to two seconds, indicating that the modal series method can capture the dynamic characteristics of the hydroelectric generating system accurately and quickly.

\subsection{First-order oscillation mode analysis}

The first-order oscillation mode reflects the natural frequency of subsystem state variables. Now, the generating system is divided into the electric subsystem, mechanical subsystem, and hydraulic

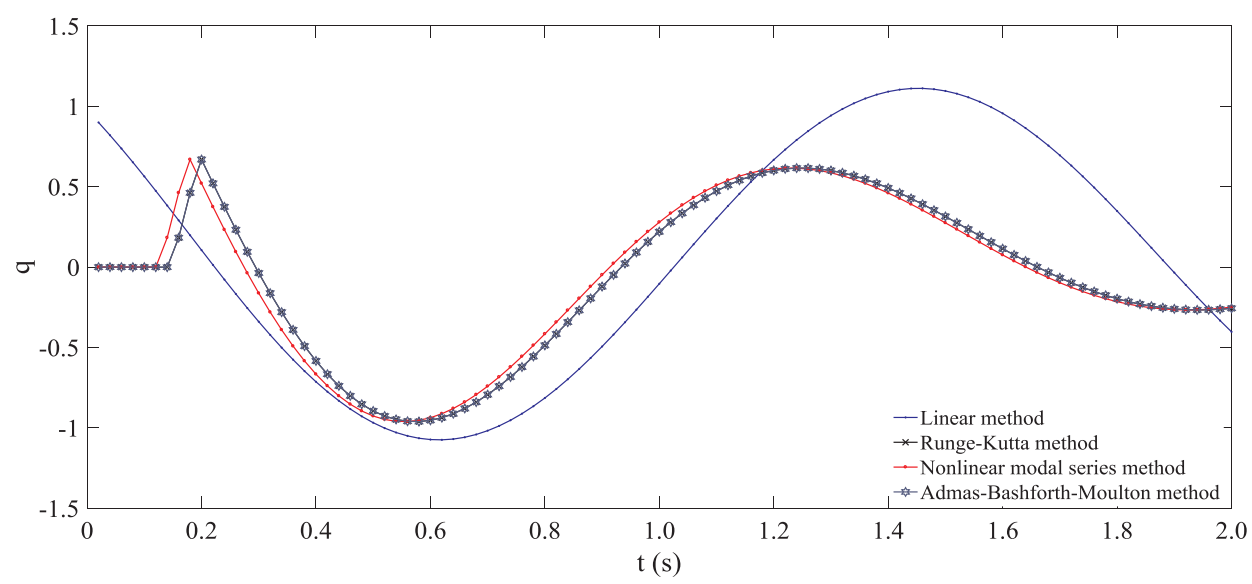

(a) The hydro-turbine flow

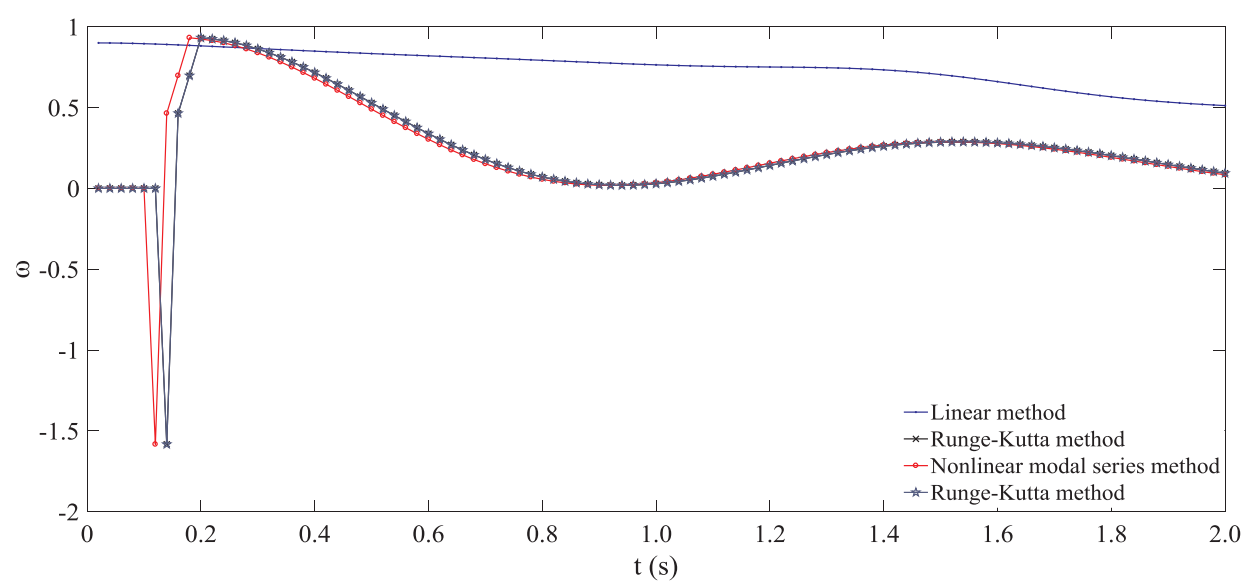

(b) The generator speed

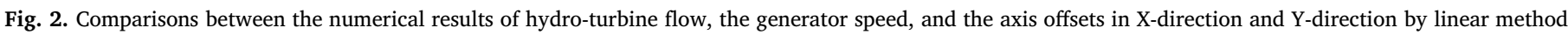

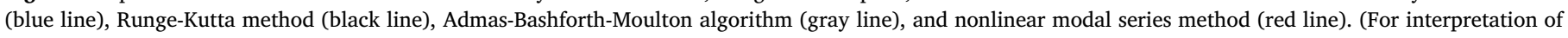
the references to color in this figure legend, the reader is referred to the web version of this article.) 


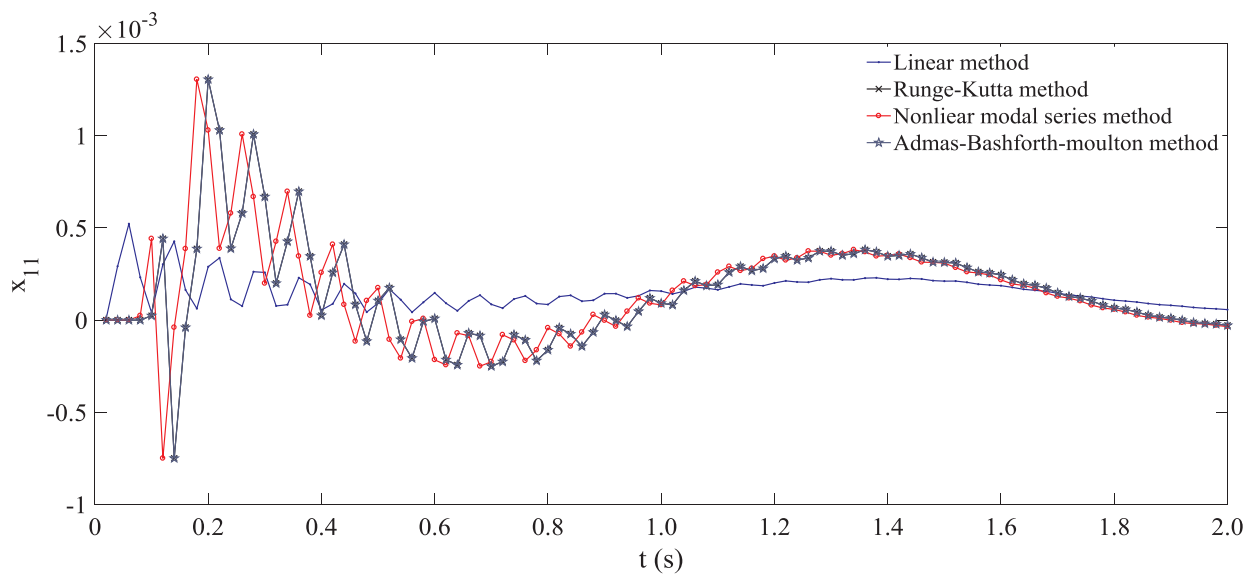

(c) Axis offset in X-direction

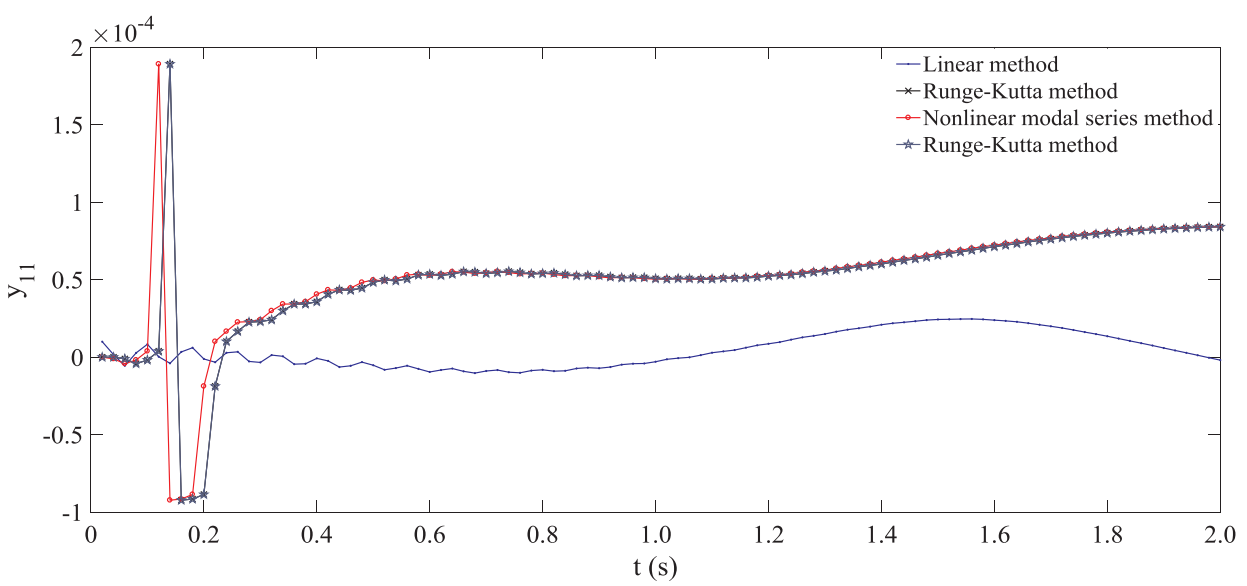

(d) Axis offset in Y-direction

Fig. 2. (continued)

subsystem. The electric subsystem includes the generator speed $(\omega)$, the power angle $(\delta)$, and the conversion efficiency (ef). The mechanical system consists of the offset of rotor axis in X-direction $\left(x_{11}\right)$, the offset of rotor axis in Y-direction $\left(y_{11}\right)$, the variation rate of rotor axis in $\mathrm{X}$ direction $\left(v_{x}\right)$, and the variation rate of rotor axis in Y-direction $\left(v_{y}\right)$. The hydraulic subsystem is composed of three state variables $\left(x_{1}, x_{2}\right.$, and $\left.x_{3}\right)$ and turbine flow $(q)$. The first-order oscillation modes $\left(P 1_{i j}\right)$ corresponding to the above three subsystems are shown in Fig. 3.

As shown in Fig. 3(a), there are three state variables driving oscillation modes in the electric subsystem: generator speed, power angle, and conversion efficiency. Specifically, for the generator speed $\omega$, the amplitudes of $\lambda_{3}, \lambda_{7}$, and $\lambda_{9}$ are higher than the others, meaning that the oscillation mode is mainly dependent on the coupling effect of oscillation modes of state variable $x_{3}$ from the hydraulic subsystem, offset $y_{11}$ and variation rate $v_{y}$ of axis in Y-direction from the mechanical system. The degree of effect is given by $x_{3}>y_{11}>v_{y}$. For the power angle $\delta$, there are three parameters with large amplitudes, $\lambda_{4}, \lambda_{6}$, and $\lambda_{11}$. The mode of vibration is directly related to modes of turbine flow $q$ and offset of axis in X-direction $x_{11}$. Their ranges are $q>x_{11}$. For the conversion efficiency $e f$, the amplitudes of $\lambda_{2}, \lambda_{3}, \lambda_{4}, \lambda_{5}$, and $\lambda_{6}$, which corresponds to state variables $x_{2}$ and $x_{3}$, turbine flow $q$, generator speed $\omega$, and offset of axis in $\mathrm{X}$-direction $x_{11}$ have large amplitudes. Their contribution to the oscillation mode of efficiency is given by $q>x_{2}>x_{3}>\omega>x_{11}$. In summary, the total contribution of state variables from the generating system is $x_{3}>q>x_{6}>x_{11}>x_{2}>y_{11}>v_{y}$. For convenience, these results are presented in Table 1 .

\subsection{Second-order oscillation mode analysis}

The strength of each mode and their contribution to overall system dynamics can be obtained. The second-order oscillation mode is excited by the combinations of two different fundamental modes, for example the combination of the first order oscillation modes $\lambda_{k}$ and $\lambda_{l}$. The index $P 2_{k l}^{i}$ can be used to analyze the second-order oscillation mode with results shown in Fig. 4.

From Fig. 4, turbine flow $q$ and amplitudes of index $P 2_{k l}^{i}$ corresponding to combinations of $\lambda_{l=2,3 ; k=3,4,5,6,7,8,9,10,11}, \lambda_{l=4,5,6 ; k=4,11}$, and $\lambda_{l=8,9,10 ; k=2,3}$ are larger other interactions. In other words, the interaction of combinations of fundamental oscillation modes of $x_{k}$ and $x_{l}$ (corresponding to $\lambda_{k}$ and $\lambda_{l}$ ) produces the second-order oscillation mode. Similarly, the interaction of combinations of $\lambda_{l=2,3 ; k=2,3,4,5,6,7,8,9,10,11}, \quad \lambda_{l=4,5,6 ; k=2,3,4,5,11}, \quad$ and $\lambda_{l=8,9,10 ; k=2,3}$ for conversion efficiency, $\quad \lambda_{l=1,2,3 ; k=5,6}, \quad \lambda_{l=4,5,6 ; k=2,3,4,5,11}, \quad$ and $\lambda_{l=9,10 ; k=2,3}$ for offset in X-direction, $\lambda_{l=5,6,11 ; k=2,3,4,5,6,11}$ and $\lambda_{l=2,3,4 ; k=5,11}$ for the turbine flow $q$ highlight novel second-order oscillation modes. According the definition of index $P 2_{k l}^{i}$, these secondorder oscillation modes play important roles in the transient processes of the generating system. Larger amplitudes of index $P 2_{k l}^{i}$ result in longer durations of these oscillation modes during transient processes. The interaction of these modes enhances the coupling effect of these subsystems, which presents challenges in controlling transient processes. 


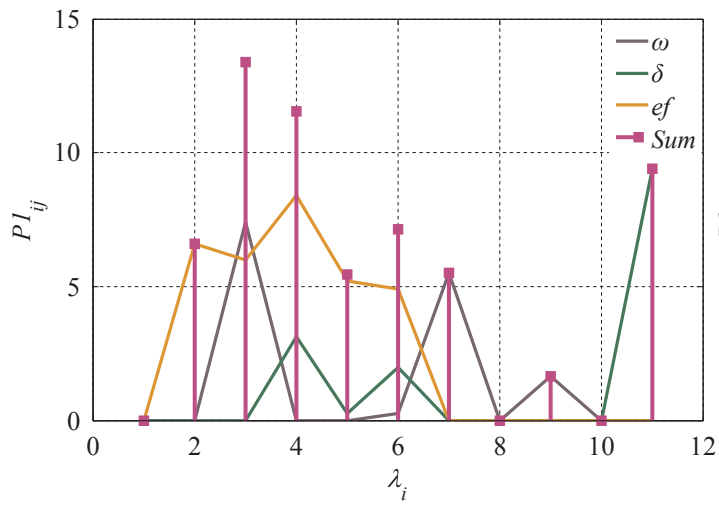

(a) Effect of $P 1_{i j}$ on the electric subsystem

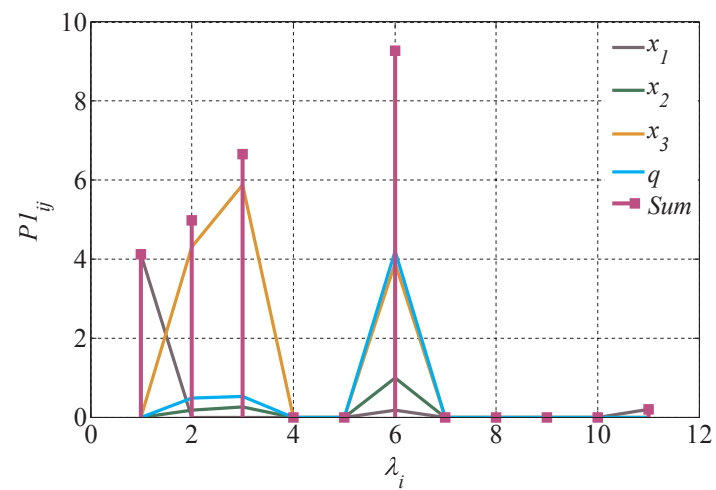

(c) Effect of $P 1_{i j}$ on the hydraulic subsystem

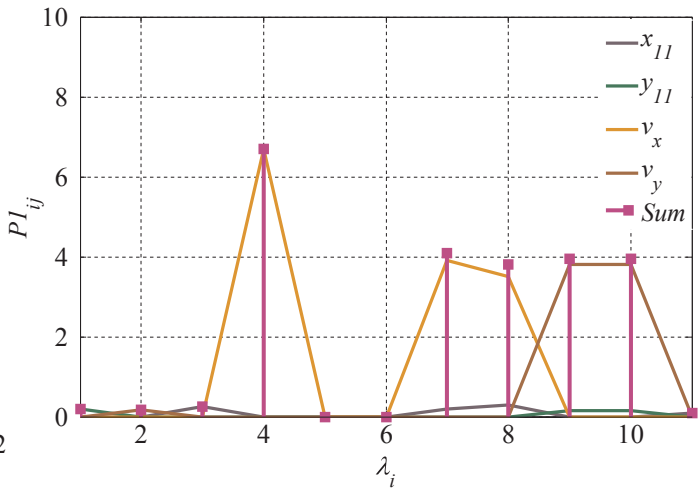

(b) Effect of $P 1_{i j}$ on the mechanical subsystem

Fig. 3. The first-order oscillation mode $\left(P 1_{i j}\right)$ of the hydroelectric generating system.

Table 1

Related oscillation modes and sorting the contributions.

\begin{tabular}{llll}
\hline System & $\begin{array}{l}\text { State } \\
\text { variable }\end{array}$ & $\begin{array}{l}\text { Related } \\
\text { oscillation } \\
\text { modes }\end{array}$ & Sorting of contribution \\
\hline Electric subsystem & $\delta$ & $q, x_{11}$ & $q>x_{11}$ \\
& $\omega$ & $x_{3}, y_{11}, v_{y}$ & $x_{3}>y_{11}>v_{y}$ \\
Sum & & $x_{3}, q, x_{6}, x_{11}$, & $x_{3}>q>x_{6}>x_{11}>x_{2}-$ \\
& & $x_{2}, y_{11}, v_{y}$ & $>y_{11}>v_{y}$ \\
Mechanical subsystem & $x_{11}$ & $x_{3}, y_{11}, v_{x}$ & $v_{x}>x_{3}>y_{11}$ \\
& $y_{11}$ & $\delta, v_{y}$ & $\delta=v_{y}$ \\
& $v_{x}$ & $q, y_{11}, v_{x}$ & $q>y_{11}>v_{x}$ \\
& $v_{y}$ & $v_{y}, \delta$ & $v_{y}=\delta$ \\
& & $q, y_{11}, v_{y}, \delta, v_{x}$ & $q>y_{11}>v_{y}=\delta>v_{x}$ \\
Sum & $x_{1}, x_{11}$ & $x_{1}>x_{11}$ \\
Hydraulic subsystem & $x_{1}$ & $x_{2}, x_{3}, x_{11}$ & $x_{11}>x_{3}>x_{2}$ \\
& $x_{2}$ & $x_{2}, x_{3}, x_{11}$ & $x_{3}>x_{11}>x_{2}$ \\
& $x_{3}, x_{3}, x_{11}$ & $x_{11}>x_{3}>x_{2}$ \\
& $q$ & $x_{11}, x_{3}, x_{2}, x_{1}$ & $x_{11}>x_{3}>x_{2}>x_{1}$ \\
& & &
\end{tabular}

\subsection{Discussions}

With the rapid development of renewable energies linked to the power grid, to improvements to the modeling accuracy of hydroelectric generating systems are crucial to increase the stability of unit performance [44]. With this in mind, this study provides a novel model of the hydroelectric generating system which couples and analyzes the shafting of the hydro-turbine generator unit, and oscillation modal interactions of hydraulic, mechanical, and electric subsystems. First, Fig. 2 and Tab. 5 show the feasibility of the nonlinear modal series method and the robustness of the model. Note that the dynamic behaviors of the model show reduced modeling accuracy when compared to Zeng's model [37] and Xu's model [38]. This is likely due to the change in the flow caused by guide vane opening. Turbine blades are generally designed to ensure that water crosses the blades smoothly at rated capacities, termed the optimum operation state. At lower capacities, the water flow state is changed due to the change of guide vane opening, leading to turbulence between the water flow and turbine blades. This turbulence changes the dynamic characteristics of turbine torque (Eq. (12)), and further lowers the modelling accuracy. Random variables could be added to the unbalanced hydraulic forces and turbine torque in order to apply this model to non-optimum turbine states (full details are in Supplementary Note 2). Second, the traditional models of the hydroelectric generating system are generally composed of the electric subsystem and the hydraulic subsystem, such as the classical model proposed by the IEEE Group [10] (without the mechanical subsystem). From the results obtained by this novel model (see Tab. 3 and Fig. 4), the first-order oscillation modes of $\delta$ and $\omega$ are directly affected by variables $x_{11}$ and $y_{11}$ (belonging to mechanical subsystem). Hence, this modeling modelling approach succeeds in coupling traditional models with the mechanical subsystem. On the basis of the model established in this study, control methods with respect to hydroelectric generating systems become a new challenge. The application of this model to real-time operational data would provide operators important information on shaft oscillation and timely mitigation options. Even if the model is too complex to operationalize in real-time by operators, the control in the oscillation mode of $x_{3}$ may already be sufficient to mitigate adverse coupling effects and second-order oscillations. This would improve the overall reliability and therefore the capacity factors of hydropower plants. 


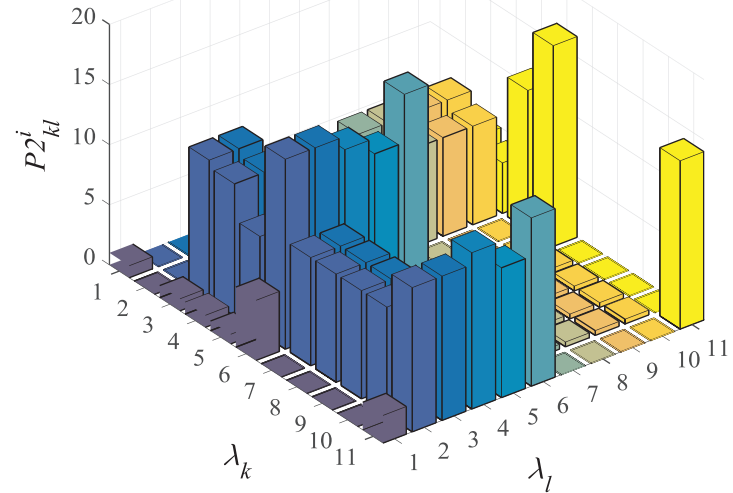

(a) Second-order mode of turbine flow

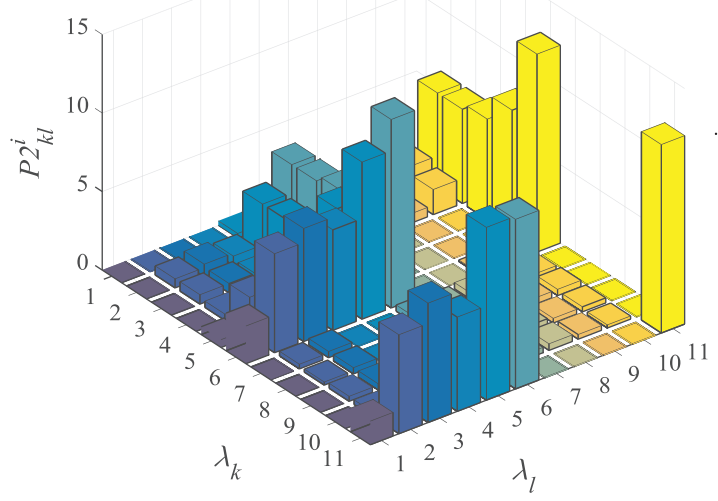

(c) Second-order mode of offset in X-direction

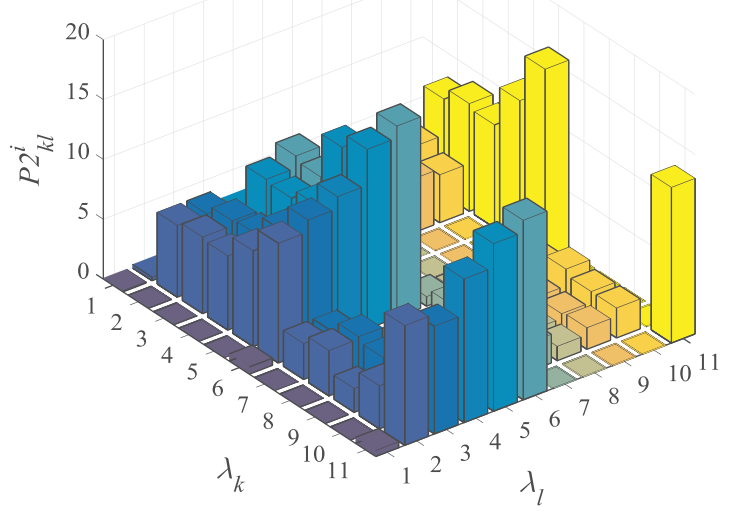

(b) Second-order mode of conversion efficiency

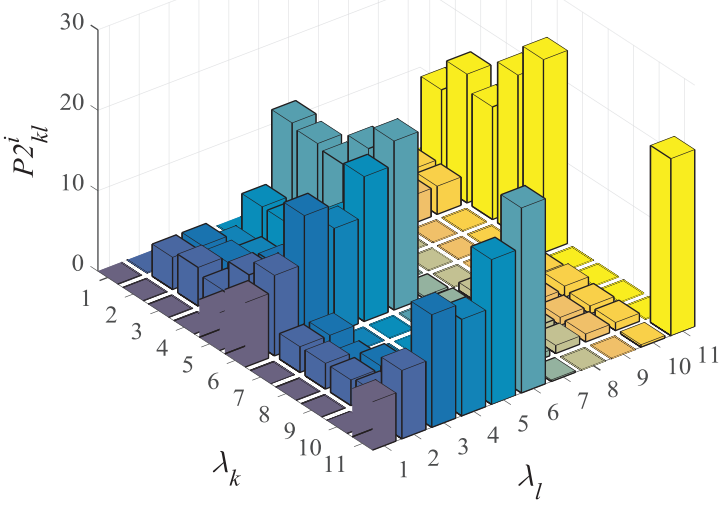

(d) Second-order mode of offset in Y-direction

Fig. 4. The second-order oscillation mode of the hydroelectric generating system.

\section{Conclusions}

In this study, a classical nonlinear mathematical model of the hydroturbine governing system with the shafting of a hydro-turbine generator unit is established. A unified model with a novel expression of the hydraulic unbalanced force acting on the runner blade is proposed and verified against two conventional models, and against measured data from the monitoring system of Nazixia hydropower station. Note that the unified model works very well when the turbine is operating close or at full capacity, and is an improvement on other models. However, at lower capacities, it performs less well than other models. Furthermore, the feasibility of the nonlinear modal series method is verified and compared with the numerical results from the linear method, RungeKutta method, and Admas-Bashforth-Moulton algorithm. On the basis of this, a first- and second-order oscillation mode analysis are performed to investigate the modal interactions of the three components in the hydroelectric generating system, namely the electric subsystem, mechanical subsystem, and hydraulic subsystem. In the electric subsystem, the results show that the first-order oscillation mode of the generator speed $\omega$ is mainly dependent on the coupling effect of oscillation modes of state variable $x_{3}$ from the hydraulic subsystem, offset $y_{11}$ in the runner blade, and variation rate $v_{y}$ of the $\mathrm{Y}$ axis in the mechanical subsystem; with the order of dependence as $x_{3}>y_{11}>v_{y}$. For the mechanical subsystem, the first-order mode of the offsets in Xand Y-direction is affected by the coupling oscillation modes of variables $x_{3}$ from the hydraulic subsystem, $v_{x}$ and $y_{11}$ from the mechanical subsystem. Their sorting of contributions are $x_{3}>v_{x}>y_{11}$. In the hydraulic subsystem, the first-order oscillation mode of the turbine flow is dependent on variables $x_{2}, x_{3}$, and $x_{11}$, and in the order of dependence of $x_{11}>x_{3}>x_{2}$.

In light of the above analysis, the unified model performs poorly at low capacities, probably due to the stochastic excitation of unbalanced hydraulic forces acting on the blades. Future work should attempt to validate this hypothesis. A second avenue for future work might include an improved design control method which uses the unified model presented here to stabilize the generator speed and the axis shift of hydro-turbine generator unit when operating at close to power capacity.

\section{Acknowledgement}

This work was supported by the scientific research foundation of National Natural Science Foundation of China-Outstanding Youth Foundation (No. 51622906), National Natural Science Foundation of China (No. 51479173), Fundamental Research Funds for the Central Universities (No. 201304030577), Scientific research funds of Northwest A\&F University (No. 2013BSJJ095), Science Fund for Excellent Young Scholars from Northwest A\&F University and Shaanxi Nova program (No. 2016KJXX-55). 


\section{References}

[1] IHA. International Hydropower Association Congress Adopts Sustainability Protocol.

[2] Ran L, Lu XX. Cooperation is key to Asian hydropower. Nature 2011;473:452.

[3] Macdonald AE, Clack CTM, Alexander A, Dunbar A, Wilczak J, Xie YF. Future costcompetitive electricity systems and their impact on $\mathrm{US} \mathrm{CO}_{2}$ emissions. Nat Clim Change 2016;6(5):526-31.

[4] Krajacic G, Duic N, Vujanovic M, Kilkis S, Rosen MA, Al-Nimr MA. Sustainable development of energy, water and enviroment systems for future energy. Energy Convers Manage 2016;125:1-14.

[5] Seleznev VS, Liseikin AV, Bryksin AA, Gromyko PV. What caused the accident at the Sayano-Shushenskaya hydroelectric power plant (SSHPP): a Seismologist's point of view. Seismol Res Lett 2014;85(4):817-24.

[6] Perez-Diaz JI, Sarasua JI, Wilhelmi JR. Contribution of a hydraulic short-circuit pumped-storage power plant to the load-frequency regulation of an isolated power system. Int J Electr Power Energy Syst 2014;62:199-211.

[7] Rahi OP, Chandel AK. Refurbishment and uprating of hydro power plants - a literature review. Renew Sustain Energy Rev 2015;48:726-37.

[8] Cheng CT, Yan LZ, Mirchi A. Madani K. China's boom hydropower: systems modeling challenges and opportunities. J Water Resour Plann Manage 2017;143(1). https://doi.org/10.1061/(ASCE)WR.1943-5452.0000723.

[9] Chaudhry MH. Applied hydraulic transients. Van Nostrand Reinhold Co; 1979.

[10] Group W. Hydraulic turbine and turbine control models for system dynamic studies. IEEE Trans Power Syst 1992;7:167-79.

[11] Xu B, Yan D, Chen D, Gao X, Wu C. Sensitivity analysis of a Pelton hydropower station based on a novel approach of turbine torque. Energy Convers Manage 2017;148:785-800.

[12] Tong W. Analysis of shaft oscillation caused by the unbalanced hydraulic force of turbine runner. Sichuan Water Power 1986:42-6.

[13] Lu YC, Li W. Study on condition assessment and fault diagnosis for converter transformers. In: 2016 IEEE international conference on high voltage engineering and application (ICHVE); 2016.

[14] Oldenburger R, Donelson J. Dynamic response of a hydroelectric plant. Power Appar Syst Part III Trans Am Instit Electr Eng 1962;81:403-18.

[15] Kundur Prabha. Power system stability and control. China Electric Power Press; 2001.

[16] Goyal R, Cervantes MJ, Gandhi BK. Vortex rope formation in a high head model Francis turbine. J Fluids Eng 2017;139.

[17] Riasi A, Tazraei P. Numerical analysis of the hydraulic transient response in the presence of surge tanks and relief valves. Renew Energy 2017;107:138-46.

[18] Xu B, Chen D, Zhang H, Wang F. Modeling and stability analysis of a fractionalorder Francis hydro-turbine governing system. Chaos Sol Fractal 2015;75:50-61.

[19] Xu B, Chen D, Tolo S, Patelli E, Jiang Y. Model validation and stochastic stability of a hydro-turbine governing system under hydraulic excitations. Int J Electr Power Energy Syst 2018;95:156-65.

[20] Li H, Chen D, Zhang H, Wu C, Wang X. Hamiltonian analysis of a hydro-energy generation system in the transient of sudden load increasing. Appl Energy 2017; 185:244-53.

[21] Xu B, Wang F, Chen D, Zhang H. Hamiltonian modeling of multi-hydro-turbine governing systems with sharing common penstock and dynamic analyses under shock load. Energy Convers Manage 2016;108:478-87.

[22] Kavurmaci B, Celebioglu K, Aradag S, Tascioglu Y. Model Testing of Francis-Type Hydraulic Turbines. Meas Contr -London- Instit Meas Contr 2017;50:70-3.

[23] M’zoughi F, Bouallegue S, Garrido AJ, Garrido I, Ayadi M. Stalling-free control strategies for oscillating-water-column-based wave power generation plants. IEEE
Trans Energy Convers 2018;33(1):209-22.

[24] Li C, Mao Y, Zhou J, Zhang N, An X. Design of a fuzzy-PID controller for a nonlinear hydraulic turbine governing system by using a novel gravitational search algorithm based on Cauchy mutation and mass weighting. Appl Soft Comput 2016;52:290-305.

[25] Mesnage H, Alamir M, Perrissin-Fabert N, Alloin Q. Nonlinear model-based control for minimum-time start of hydraulic turbines. Eur J Contr 2017;34:24-30.

[26] Liang J, Yuan XH, Yuan YB, et al. Nonlinear dynamic analysis and robust controller design for Francis hydraulic turbine regulating system with a straight-tube surge tank. Mech Syst Sig Process 2017;85:927-46.

[27] Guo WC, Yang JD. Stability performance for primary frequency regulation of hydroturbine governing system with surge tank. Appl Math Model 2018;54:446-66.

[28] Guo WC, Yang JD. Modeling and dynamic response control for primary frequency regulation of hydro-turbine governing system with surge tank. Renew Energy 2018;121:173-87.

[29] Zhang CB, Yang MJ, Li JY. Detailed modelling and parameters optimisation analysis on governing system of hydro-turbine generator unit. IET Gener Transm Distrib 2018;12(5):1045-51.

[30] Cardinali R, Nordmann R, Sperber A. Dynamic simulation of non-linear models of hydroelectric machinery. Mech Syst Sig Process 1993;7:29-44.

[31] Afzal M, Arteaga IL, Kari L. Numerical analysis of multiple friction contacts in bladed disks. Int J Mech Sci 2018;137:224-37.

[32] Gibbons CB. Coupling misalignment forces; 1976.

[33] Luo SY, Zhu DH, Hua L, Qian DS, Yan SJ. Numerical analysis of die wear characteristics in hot forging of titanium alloy turbine blade. Int J Mech Sci 2017;123:260-70.

[34] Donát M. Computational modelling of the unbalanced magnetic pull by finite element method. Proc Eng 2012;48:83-9.

[35] Frost CH, Evans PS, Harrold MJ, Masonjones A, O'Doherty T, O'Doherty DM, et al. The impact of axial flow misalignment on a tidal turbine. Renew Energy 2017;113:1333-44.

[36] Fu XQ, Jia WT, Xu H, Song SL. Imbalance-misalignment-rubbing coupling faults in hydraulic turbine vibration. Optik - Int J Light Electr Opt 2016;127:3708-12.

[37] Zeng Y, Zhang LX, Guo YK, Qian J, Zhang CL. The generalized Hamiltonian model for the shafting transient analysis of the hydro turbine generating sets. Nonlin Dyn 2014;76(4):1921-33.

[38] Xu B, Chen D, Zhang H, Zhou R. Dynamic analysis and modeling of a novel fractional-order hydro-turbine-generator unit. Nonlin Dyn 2015;81:1263-74.

[39] Pariz N, Shanechi HM, Vaahedi E. Explaining and validating stressed power systems behavior using modal series. IEEE Trans Power Syst 2003;18(2):778-85.

[40] Khatibi M, Shanechi HM. Using modal series to analyze the transient response of oscillators. Int J Circuit Theory Appl 2011;39(2):127-34.

[41] Chen T, Zheng XH, Zhang YN, Li SC. Influence of upstream disturbance on the drafttube flow of Francis turbine under part-load conditions. J Hydrodyn 2018;30(1):131-9.

[42] Zhang YN, Chen T, Li JW, Yu JX. Experimental study of load variations on pressure fluctuations in a prototype reversible pump turbine in generating mode. J. Fluids Eng-Trans ASME 2017;139(7). https://doi.org/10.1115/1.4036161.

[43] Kim T, Feng D, Jang M, Agelidis VG. Common mode noise analysis for cascaded boost converter with silicon carbide devices. IEEE Trans Power Electron 2016;32(3):1917-26.

[44] Yang WJ, Norrlund P, Saarinen L, et al. Burden on hydropower units for short-term balancing of renewable power systems. Nat Commun 2018. https://doi.org/10. 1038/s41467-018-05060-4.

[45] Bhalekar S, Daftardar-Gejji V, Baleanu D, et al. Fractional bloch equation with delay. Comput Math Appl 2011;61(5):1355-65. 